\title{
A Venous Malformation of Left Thigh-A Case Report
}

\author{
A. K. Al Miraj ${ }^{1 *}$, H. N. Ashikur Rahaman², Md. Magfur Rahman ${ }^{3}$, Md. Saif Ullah Khan ${ }^{4}$
}

\begin{abstract}
${ }^{1}$ Research Assistant, Department of Vascular Surgery, Bangabandu Sheikh Mujib Medical University (BSMMU), Dhaka, Bangladesh
${ }^{2}$ Registrar, Dept. of Clinical Oncology, Enam Medical College \& Hospital, Savar, Dhaka, Bangladesh

${ }^{3}$ Cardiac Surgeon \& Consultant Cardiologist \& Diabetologist, Department of Cardiac Surgery, Bangabandu Sheikh Mujib Medical University (BSMMU), Dhaka, Bangladesh

${ }^{4}$ Associate Professor \& Chairman, Department of Vascular Surgery, Bangabandu Sheikh Mujib Medical University (BSMMU), Dhaka, Bangladesh
\end{abstract}

DOI: $10.36347 /$ simcr.2020.v08i01.019

| Received: 27.12.2019 | Accepted: 07.01.2020 | Published: 22.01 .2020

*Corresponding author: A. K. Al Miraj

Abstract

Purpose: To represent the clinical usefulness of duplex-guided compression in the evaluation and treatment of iatrogenic femoral pseudo- aneurysms. Case Report: A 14 year old female patient presented to Department of Vascular Surgery BSSMU with a complaint of swelling on the left medial aspect of thigh since birth. She underwent surgical intervention twice at the age of 7 years and 12 years. However the lesion kept growing recurrently over the left medial thigh after two surgical interventions over the period of 7 years. The lesion was present on left medial aspect of thigh, extending from mid thigh to knee joint. The swelling was measuring around $7.5 \mathrm{~cm} \times 4.0 \mathrm{~cm}$. The overlying skin was normal. There was longitudinal scar marks of the previous surgery were seen. The swelling was soft, compressible and non tender on palpation. The overlying skin was normal borders were ill defined and diffuse. There was no bruit, thrill, pulsation or rise in temperature. Duplex ultrasound scanning was done to confirm the diagnosis, which revealed and MRI was done before planning for surgery to see the extent and nature of the lesion. Conclusions: This case revealed that In case of vascular malformation, soft tissue and skeletal overgrowth is a common problem with lesions specially when sited around the growth plates of the long bones. Surgical excision should be the line of treatment and ensures least down time, morbidity and recurrence rate. Clinicians dealing with vascular problems should be aware of this lesion where early surgical intervention provides optimal results, however should also keep in mind that recurrence of such kind of lesion is high.

Keywords: Vascular Malformation (VM); Haemangioma; Duplex ultrasound.

Copyright @ 2020: This is an open-access article distributed under the terms of the Creative Commons Attribution license which permits unrestricted use, distribution, and reproduction in any medium for non-commercial use (NonCommercial, or CC-BY-NC) provided the original author and source are credited.

\section{INTRODUCTION}

Vascular lesions are among the most common congenital and neonatal abnormalities. Many terms are used to refer to this lesion, notably, arteriovenous aneurysm, cavernous haemangioma, central haemangioma, pulsatile haemangioma, angioma, arteriovenous shunt, arteriovenous malformation [1]. Before 1980s, vascular lesions were referred to as "haemangiomas" [2]. An understanding of vascular lesions has been greatly facilitated by the work of Mulliken and Glowacki [3]. Thereafter the vascular lesions were subdivided into haemangiomas and vascular malformations [4]. These lesions are the result of an embryologic abnormality of the vascular system. Haemangiomas are caused by a failure of differentiation in the early stages of embryogenesis. Usually they are extraosseous, more commonly appear in childhood and tend to regress or disappear in adolescence. They are rarely associated with fatal haemorrhages [5]. Venous malformations are caused by a disturbance in the late stages of angiogenesis (trunal stage) and result in the persistence of arteriovenous anastomosis present during embryonic life [3] they may be capillary, lymphatics, venous, arterial or mixed. They occur equally in males and females. All vascular malformations are present at birth. Although not clinically evident initially they may appear at different stages of life. The main characteristic feature of vascular malformations is that they never show signs of involution [6]. Capillary, lymphatic and venous malformations are classified as "low-flow" lesions. Arterial and arteriovenous malformations are often referred as "high-flow" vascular malformations and are often the cause of massive, sometimes fatal haemorrhages [6]. There are different treatment modalities, depending on the depth of the vascular malformation present, its anatomical location and extent. 


\section{Case Report}

A 14 year old female patient presented to Department of Vascular Surgery, BSMMU with a complaint of swelling on the left medial aspect of thigh since birth. She underwent surgical intervention twice at the age of 7 years and 12 years. However the lesion kept growing recurrently over the left medial thigh after two surgical interventions over the period of 7 years, details of the surgical findings were not known. Currently she presented with the swelling and pain for last one year. Swelling was increasing in nature and disappear specially while lying flat and after compression. Pain occurs specially while walking for long period of time. However there was no history of discoloration of the swelling and ulceration over the swelling. For pain she was having NSAIDS regularly. The lesion was present on left medial aspect of thigh, extending from mid thigh to knee joint. The swelling was measuring around $7.5 \mathrm{~cm} \times 4.0 \mathrm{~cm}$. The overlying skin was normal. There was longitudinal scar marks of the previous surgery were seen. The swelling was soft, compressible and non tender on palpation. The overlying skin was normal borders were ill defined and diffuse. There was no bruit, thrill, pulsation or rise in temperature. The following investigations were carried out to reach the diagnosis. Duplex Scan revealed multiple hypo-echoic areas within the swelling, Hypoechoic areas contains venous type of blood flow. No arterio-vennous connection was detected Shown in Figure 1-4. MRI revealed mild swelling on the medial aspect of knee joint. Multiple nodular and tubular structures denoting dilated and tortuous vessels giving seperntine like appearance within the muscles of the anterior medial aspect of lower part of thigh involving vastus medialis, vastus intermedius and part of the adductor magnus muscles, hypointense on T1 against the muscular high signal fatty tissue. On T2 and T2 FATSAT sequences the structures are hyperintense. This area is measured about $7.98 \mathrm{~cm} X 3.87 \mathrm{~cm}$. Impression suggestive of vascular malformation. FNAC report suggested that the swelling was vascular malformation.

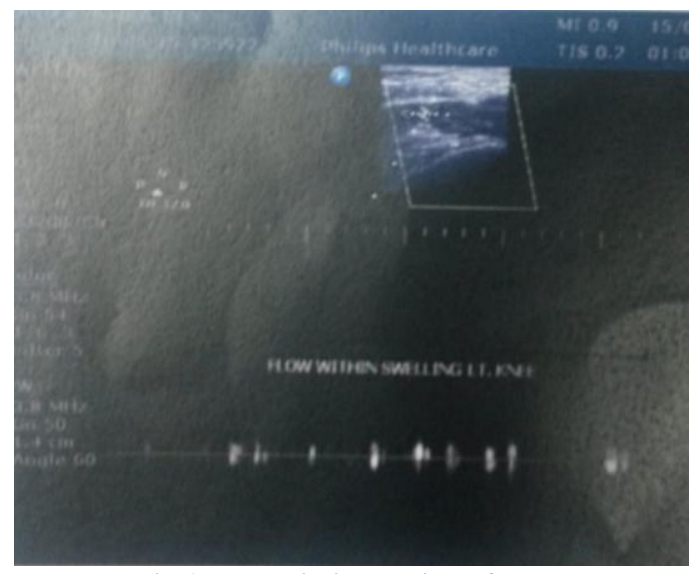

Fig-1: Flow within swelling left knee

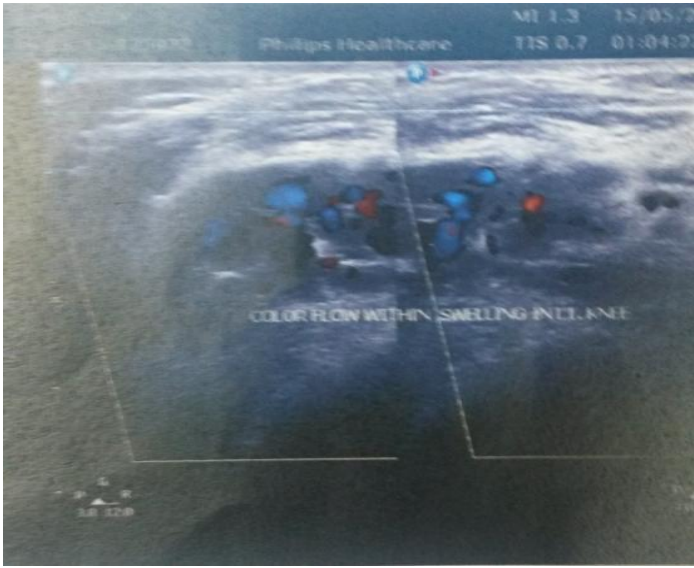

Fig-2: Color flow within swelling in left knee

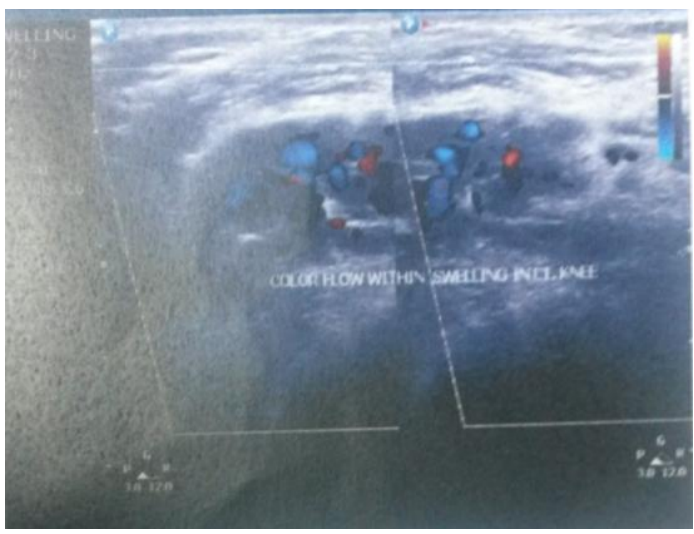

Fig-3: Color flow with swelling on the left knee

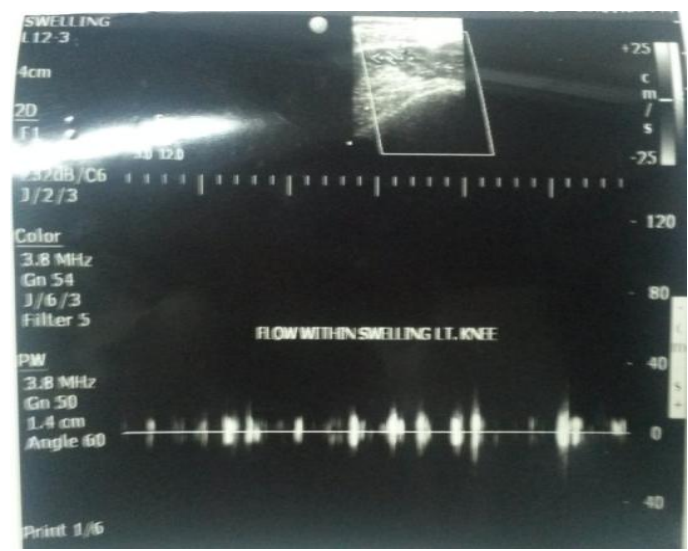

Fig-4: Flow within swelling in left knee

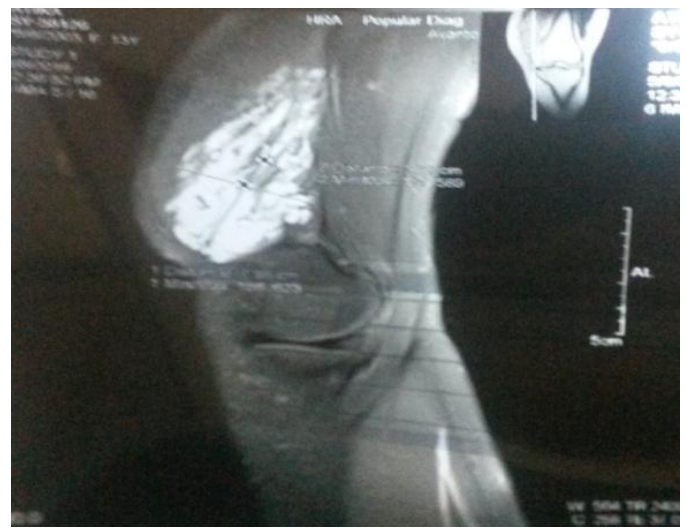

Fig-5 


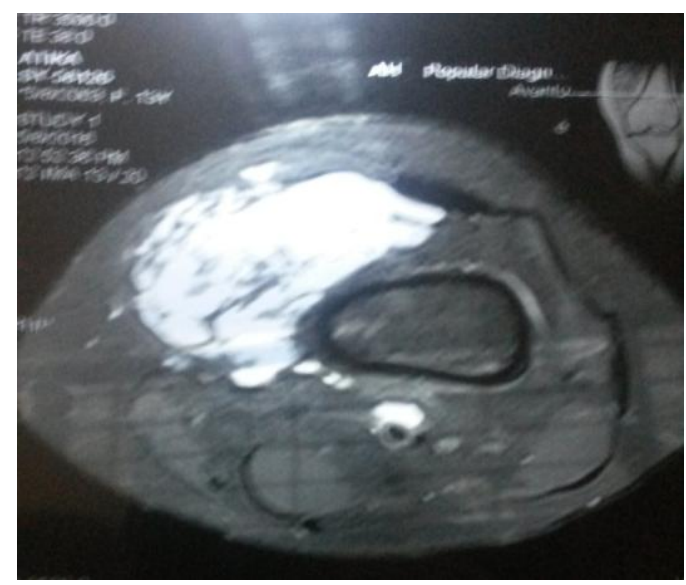

Fig-6

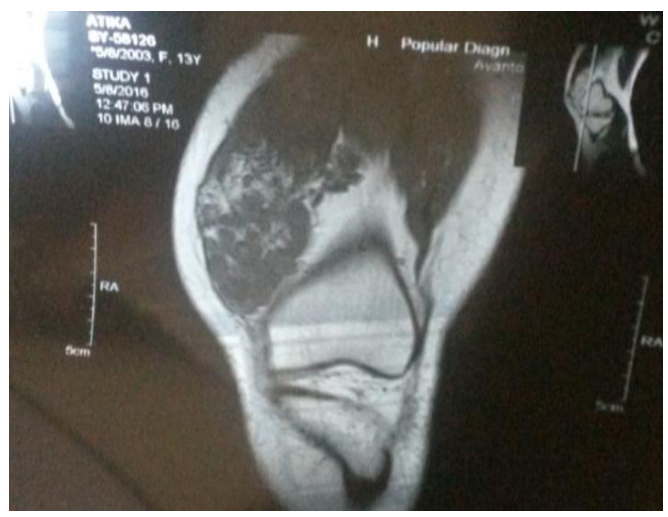

Fig-7

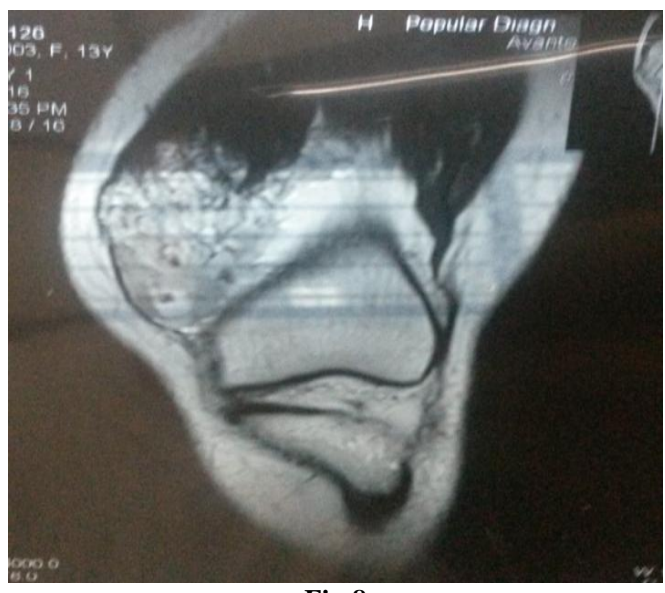

Fig-8

\section{DiscUSSION}

Vascular lesions can be divided into two major types with distinct clinical characteristics. The first type is designated as hemangiomas. These lesions are present at birth $40 \%$ of the time, usually appearing as a small red mark, with a female predilection of 5:1. They typically show rapid neonatal growth characterized by endothelial cellular hyperplasia and proliferation in the proliferative phase, followed by slow regression to a variable extent characterized by diminished cellularity and fibrofatty deposition in the involuting phase. The second type is designated as vascular malformations.
These lesions are recognized at birth $90 \%$ of the time with no sex predilection. They grow commensurately with the child and do not regress. Histologically they are characterized by "mature" endothelium that are not hypercellular and show a normal endothelial cell cycle. They may have any combination of capillary, venous, arterial, and lymphatic components, with or without fistulas, although most of these lesions are predominantly venous in type. This cell-oriented analysis has since gained wide acceptance because of its diagnostic applicability, which helps in planning therapy [7]. Venous malformations have an incidence of one to two in 10,000 births, prevalence of $1 \%$, are present at birth and grow proportionately with age causing various clinical presentations [8]. Histological abnormalities of the smooth muscle-pericyte component within vascular channel walls of VMs are hypothesised as a potential cause of many VMs [9]. There are many approaches to treat the vascular malformations. In this case total excision of the vascular malformation with ligation of the vessel were done. In general, laser therapy and an embolization followed by surgical excision are the most favourable treatment modalities. Embolization consists of occluding the vessel contributing to the lesion. Several materials such as Polyvininyl alcohol, particles, muscle, Gelfoam, Cynoacrylate, metal coils, collagen etc have been used [8]. Blood is redirected to the collaterals which are angiographically invisible due to limited perfusion, dilate as a result of the haemodynamic change and reirrigate the malformation, because of this lesion may occur. Hence the embolization confined with surgical treatment is still the most conventional modern approach [10].

\section{Conclusion}

In case of vascular malformation, soft tissue and skeletal overgrowth is a common problem with lesions specially when sited around the growth plates of the long bones, lower limb overgrowth causes a limp and a painful scoliosis may develop if the leg discrepancy is not recognized and corrected. Surgical excision should be the line of treatment whenever the clinical entity is recognized. Surgery ensures least down time, morbidity and recurrence rate. Clinicians dealing with vascular problems should be aware of this lesion where early surgical intervention provides optimal results, however should also keep in mind that recurrence of such kind of lesion is high.

\section{REFERENCES}

1. Garzan MC, Enjolras O, Frieden IJ. Vascular tumors and vascular malformations: Evidence for an association. J Am Acad Dermatol. 2000: 42; 275-279.

2. Kula K, Blakey G, Wright J, Terry BC. High flow vascular malformations: literature review and case report. Pediatr Dent. 1996:18(94);322-327. 
3. Mutliken JB, Glowacki J. Hemangiomas and vascular malformations of infants and children: a classification based endothelial characteristics. Plast Reconst Surg. 1982:69; 412-422.

4. Glowacki J, Mulliken JB. Mast cells in hemangioma and vascular malformations. Pediatrics. 1982: 70(1); 48-51.

5. Larsen PE, Peterson LJ. A systematic approach to management of high-flow vascular malformations of the mandible. Journal Oral Maxillofac Surg. 1993: 51(1); 62-69.

6. Fishman SJ, Mulliken JB: Hemangiomas and vascular malformations of infancy and childhood. Ped Surg. 1993:40; 1177-1200.

7. Meyers MA. Hemangioma of the external jugular vein. Radiology. 1967; 89:483-485.
8. Olivares JL, Rodríguez G, Fernández JA, de Gregorio MA. Jugular venous malformation in an 8-year-old boy: treatment with endovascular sclerotherapy. European journal of pediatrics. 2001 May 1;160(6):392-394.

9. Ahuja AT, Yuen HY, Wong KT, King AD, Abdullah V, To E, Chau YP, Ma KF. External jugular vein vascular malformation: sonographic and MR imaging appearances. American journal of neuroradiology. 2004 Feb 1;25(2):338-342.

10. Mulliken JB, Glowacki J. Hemangiomas and vascular malformations in infants and children: a classification based on endothelial characteristics. Plastic and reconstructive surgery. 1982 Mar;69(3):412-422. 